\title{
Cancer incidence, stage at diagnosis and outcomes among Manitoba First Nations people living on and off reserve: a retrospective population-based analysis
}

\author{
Tara C. Horrill BN RN, Lindsey Dahl MSc, Esther Sanderson, Garry Munro, Cindy Garson, \\ Randy Fransoo PhD, Genevieve Thompson PhD RN, Catherine Cook MD MSc, Janice Linton MLS, \\ Annette S.H. Schultz PhD RN
}

\section{Abstract}

Background: Substantial cancer-related disparities exist between First Nations and non-Indigenous Canadians. The objectives of this study were to compare cancer incidence, stage at diagnosis and mortality outcomes between Status First Nations people living on reserve and off reserve in Manitoba.

Methods: We conducted a retrospective analysis of population-level administrative health databases in Manitoba. Cancers diagnosed between Apr. 1, 2004, and Mar. 31, 2011, were linked with the Indian Registry System and 5 provincial databases. We compared differences in baseline characteristics, cancer incidence, site and stage at diagnosis between Status First Nations patients living on and off reserve. Linear regression models examined trends in annual cancer incidence. Cox proportional hazard regression models examined mortality.

Results: There were 1524 newly diagnosed cancers among Status First Nations people in Manitoba between Apr. 1, 2004, and Mar. 31, 2011. First Nations people living on reserve were significantly older than those living off reserve $(p<0.001)$ and had higher Charlson Comorbidity Index scores at diagnosis $(p=0.01)$. A lower proportion of on-reserve patients than off-reserve patients were diagnosed with stage I cancers $(21.7 \%$ v. $26.9 \%, p=0.02)$. There were no differences in annual cancer incidence between groups. The adjusted incidence of cancer over the combined study years was higher in the off-reserve group than in the on-reserve group (287.9 v. 247.9 per $100000, p=0.02$ ). No significant differences in mortality were found.

Interpretation: The lower proportion of on-reserve patients diagnosed with cancer at stage I is concerning, as it suggests less access to screening services or delays in diagnosis. Further research is needed to understand patterns in diagnosis and differences in cancer site and overall cancer incidence between First Nations people living on and off reserve.

ancer and other chronic diseases are leading causes of morbidity and mortality among First Nations people in Canada, and addressing the cancer burden is a growing health priority among First Nations people. ${ }^{1-4}$ Compared to non-Indigenous Canadians, First Nations people in Canada experience a higher incidence of cancers of the kidney, ${ }^{2,5-9}$ liver, ${ }^{2,7,10}$ gallbladder, ${ }^{6,9,10}$ cervix, ${ }^{2,5,7-12}$ and colon and rectum. ${ }^{2,7,8,10,13}$ Emerging evidence also indicates that First Nations people are more likely to be diagnosed with cancers at later stages than non-Indigenous Canadians $^{13-16}$ and experience significantly lower survival. ${ }^{8,10,17-19}$ Multiple factors contribute to these disparities, including individual patient factors, environmental exposures, socioeconomic factors (particularly income) and access to health care services. $^{2,8,20,21}$

About half of First Nations people in Manitoba live on designated tracts of land known as reserves ${ }^{22}$ located throughout the province. The funding and delivery of health care services to First Nations living on reserves is limited, and the effects on health outcomes of limited access to some health care services for First Nations peoples (both Status and non-Status) living on reserve are not clear. Differences in the funding and delivery of health care services to First Nations on and off reserve can have important impacts on individual and population health.

We report on the findings from a larger study of provincial health administrative data ${ }^{16}$ to address 3 objectives: 1 ) to

Competing interests: None declared.

This article has been peer reviewed.

Correspondence to: Tara Horrill, Tara.horrill @ umanitoba.ca

CMAJ Open 2019. DOI:10.9778/cmajo.20190176 
describe the demographic characteristics, comorbidities, and site and stage of cancer at diagnosis in Status First Nations people living on and off reserve who received a cancer diagnosis between Apr. 1, 2004, and Mar. 31, 2011;2) to compare annual cancer incidence rates for the 2 cohorts; and 3 ) to investigate mortality outcomes for the 2 cohorts.

\section{Methods}

\section{Setting}

Roughly 11\% (130 505) of Manitoba residents self-identify as First Nations, with the majority (10\% of Manitoba residents) identifying as Status First Nations ${ }^{23}$ (people registered under the Indian Act, which entitles them to live on reserves ${ }^{22}$ ). In 2016, 52\% of Status First Nations people lived in a First Nations communities (known as reserves; $n=63$ ) in Manitoba. ${ }^{22}$

The provision of health care services is not entirely similar between Status First Nations people living on reserve and those living off reserve. In general, health care services in Canada are publicly funded, providing universal coverage for medically necessary hospital and generalist and specialist physician services to all residents. In addition, Status First Nations people are eligible for the federal Non-Insured Health Benefits Program, which provides a range of services not covered by other insurance programs. The federal government also funds or delivers public health services and limited primary health care to Status First Nations people living on reserve. However, many First Nations communities are located in remote areas of Manitoba with severely limited access to medically necessary services provided in hospitals and by physicians.

\section{Study design and data sources}

We conducted a retrospective study of cancer incidence and 5 -year mortality among Status First Nations people living on and off reserve using administrative health data housed in the Manitoba Centre for Health Policy Population Research Data Repository. Data files in the repository do not contain names or other identifying information; an encrypted identifier allows linkage across files at the individual level while protecting privacy. We identified and included all Status First Nations people with any newly diagnosed cancer (excluding nonmelanoma and in situ skin cancers) between Apr. 1, 2004, and Mar. 31, 2011, in Manitoba. Seven data sets within the Manitoba Centre for Health Policy repository were used (Appendix 1, available at www.cmajopen.ca/content/7/4/ E754/suppl/DC1).

Linkage of the Manitoba Health Insurance Registry and the Indian Registry System was used to create a file of First Nations patients and was approved through the research protocols of the Assembly of Manitoba Chiefs before 2014 and Nanaandawewigamig First Nations Health and Social Secretariat of Manitoba thereafter. The First Nations file was linked to the Manitoba Cancer Registry to identify all newly diagnosed cancers among Status First Nations people. The registry maintains a high degree of data completeness: Lix and colleagues $^{24}$ reported $100 \%$ linkage of anonymized patientspecific identification variables in both the Manitoba Cancer
Registry data and administrative data in the repository at Manitoba Centre for Health Policy. The First Nations file was then linked to hospital abstracts, medical claims, the 2006 Canada census and Vital Statistics Mortality Registry files.

\section{Outcomes}

The primary outcome examined was all-cause mortality. Patients were followed for 5 years from the date of cancer diagnosis. We explored 5-year cancer-specific mortality as a secondary outcome.

\section{Variables}

Variables measured at the time of diagnosis included age, sex, region of residence, area-level income, Charlson Comorbidity Index score, and cancer stage and site. We used 2 measures of region of residence: Regional Health Authority, and on or off reserve. Manitoba is divided geographically into 5 Regional Health Authority regions; each authority is responsible for the delivery of health services within its area. Patient residential postal code within the Indian Registry System data file identified residence as on or off reserve.

We categorized patients into area-level income quintiles based on average household incomes calculated for each census dissemination area. We calculated separate income quintiles for urban and rural residents using 2006 census data. For income quintiles, urban residents referred to those living in 1 of Manitoba's 2 largest cities (Winnipeg and Brandon), and rural residents referred to those living in all other areas. Both the method to assign urban or rural status and the Regional Health Authority method are based on patient residential postal codes and municipal codes.

We used the Charlson Comorbidity Index to determine each patient's health status at the time of diagnosis. ${ }^{25}$ This instrument is a weighted index estimating 1-year mortality risk that accounts for the number and seriousness of comorbid conditions, including cancer and cardiac, vascular, renal, hepatic and neurologic diseases; higher scores indicate higher burden of disease and risk of death. ${ }^{26}$ It is a valid and reliable measure of comorbidities based on a person's medical history. ${ }^{27-29}$ Each comorbidity category has specific codes of the clinical modification of the International Classification of Diseases, 9th Revision and the 10th Revision of the International Statistical Classification of Diseases and Related Health Problems, enhanced Canadian version, ${ }^{30}$ which we found in the hospital discharge abstract and medical claims databases during the 1-year period before cancer diagnosis.

We categorized cancer stage using the American Joint Committee on Cancer Staging system, ${ }^{31}$ which ranges from stage I (least severe) to IV (most severe) based on tumour characteristics. We also used a fifth category to categorize patients with cancers that could not be assessed. We determined cancer site from the Manitoba Cancer Registry, based on the International Classification of Diseases for Oncology, Third Edition.

\section{Statistical analysis}

We analyzed the data on the secure server at the Manitoba Centre for Health Policy using SAS statistical software, V9.4 
(SAS Institute). We conducted descriptive analysis and comparisons of characteristics at time of cancer diagnosis between on- and off-reserve Status First Nations groups. We used $\chi^{2}$ tests to test for significant differences in sex, urban/rural residency, Regional Health Authority residency, income quintile, cancer site and cancer stage at diagnosis, and $t$ tests to compare group averages for age and Charlson Comorbidity Index score.

\section{Cancer incidence}

We calculated annual cancer incidence for each fiscal year from $2004 / 05$ to $2010 / 11$. We determined separate rates for on- and off-reserve populations by identifying the number of Status First Nations people with a cancer diagnosed each year divided by the annual population counts of on- and offreserve First Nations people in Manitoba (using the Indian Registry System). We tested differences in annual crude incidence rates and the cumulative incidence rate over the 7-year period between on- and off-reserve Status First Nations populations for significance using $\chi^{2}$ tests. To account for demographic differences between on- and off-reserve populations, we estimated adjusted rates using a generalized linear model with a negative binomial log link function. This model controlled for age, sex, income quintile and Regional Health Authority area of residence. We analyzed trends over time with linear regression models fit to the annual rates.

\section{Mortality}

We used Cox proportional hazard regression models to compare the risk of mortality between on- and off-reserve Status First Nations patients. We measured time to death in days from the date of cancer diagnosis to the date of death. Patient data were censored at 5 years if the patient was still alive or at the time of discontinuation of health insurance coverage, which usually indicates that the person has moved out of Manitoba. In the analysis of cancer-specific mortality, we censored patient data at the time of death for all non-cancerrelated causes of death. Potential confounding variables accounted for in the analyses included age, sex, Charlson Comorbidity Index score, cancer stage, income quintile and Regional Health Authority area of residence. All effect estimates are reported as hazard ratios (HRs) with 95\% confidence intervals (CIs). The significance level was set as $p<0.05$.

\section{Ethics approval}

Ethics approval for this study was obtained from the University of Manitoba Education/Nursing Research Ethics Board, the Manitoba Health Information Privacy Committee, CancerCare Manitoba and the Health Information Research Governance Committee at Nanaandawewigamig.

\section{Results}

\section{Patient characteristics}

There were 1524 newly diagnosed cancers among Status First Nations people in Manitoba between Apr. 1, 2004, and
Mar. 31, 2011. On average, those living on reserve were older than those living off reserve (mean 60.6 v. $57.5 \mathrm{yr}, p<0.001$ ) and had a higher mean Charlson Comorbidity Index score (1.4 v. $1.3, p=0.01$ ) (Table 1). In both groups, a higher proportion of women than of men were newly diagnosed with cancer.

\section{Cancer diagnoses by stage and site}

A significantly lower proportion of on-reserve patients than off-reserve patients were diagnosed at stage I $(21.7 \% \mathrm{v}$. $26.9 \%, p=0.02$ ) (Table 2). No other significant differences in stage at diagnosis were found between the 2 groups. There were significantly lower proportions of patients with breast and cervical cancers, and significantly higher proportions of

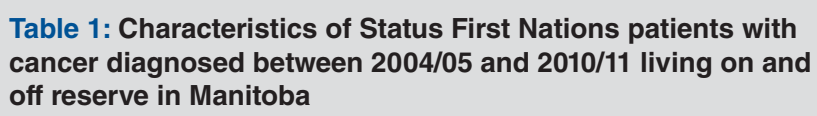

\begin{tabular}{|lccc|}
\hline & \multicolumn{2}{c}{ No. (\%) of patients ${ }^{*}$} & \\
\cline { 2 - 3 } Characteristic & $\begin{array}{c}\text { On reserve } \\
n=930\end{array}$ & $\begin{array}{c}\text { Off reserve } \\
n=594\end{array}$ & $p$ value \\
\hline Age, yr, mean \pm SD & $60.6 \pm 14.5$ & $57.5 \pm 14$ & $<0.001$ \\
\hline Sex & & & \\
\hline Male & $456(49.0)$ & $223(37.5)$ & $<0.001$ \\
\hline Female & $474(51.0)$ & $371(62.5)$ & \\
\hline Rural residency & $846(91.0)$ & $266(44.8)$ & \\
\hline
\end{tabular}

Regional Health

$<0.001$

Authority

\begin{tabular}{|lcc|}
\hline Interlake Eastern & $257(27.6)$ & $81(13.6)$ \\
\hline Northern & $428(46.0)$ & $107(18.0)$ \\
\hline Southern & $6(0.6)$ & $7(1.2)$ \\
\hline Prairie Mountain & $68(7.3)$ & $20(3.4)$ \\
\hline Winnipeg & $102(11.0)$ & $66(11.1)$ \\
\hline Public Trustee & $69(7.4)$ & $313(52.7)$ \\
\hline Income quintile & & \\
\hline NF & $12(1.3)$ & $9(1.5)$ \\
\hline R1 (lowest rural) & $508(54.6)$ & $79(13.3)$ \\
\hline R2 & $209(22.5)$ & $43(7.2)$ \\
\hline R3 & $43(4.6)$ & $43(7.2)$ \\
\hline R4 & $75(8.1)$ & $51(8.6)$ \\
\hline R5 (highest rural) & $11(1.2)$ & $50(8.4)$ \\
\hline U1 (lowest urban) & $49(5.3)$ & $170(28.6)$ \\
\hline U2 & $12(1.3)$ & $67(11.3)$ \\
\hline U3 & $\leq 5$ & $38(6.4)$ \\
\hline U4 & $\leq 5$ & $32(5.4)$ \\
\hline U5 (highest urban) & $\leq 5$ & $12(2.0)$ \\
\hline $\begin{array}{l}\text { Charlson Comorbidity } \\
\text { Index score, mean } \\
\pm \text { SD }\end{array}$ & $1.4 \pm 1.4$ & $1.3 \pm 1.3$ \\
\hline $\begin{array}{l}\text { Note: NF = not found, SD }=\text { standard deviation. } \\
{ }^{*} \text { Except where noted otherwise. }\end{array}$ & \\
\hline
\end{tabular}




\begin{tabular}{|c|c|c|c|}
\hline \multirow[b]{2}{*}{ Variable } & \multicolumn{2}{|c|}{ No. (\%) of patients } & \multirow[b]{2}{*}{$p$ value } \\
\hline & On reserve & Off reserve & \\
\hline \multicolumn{4}{|l|}{ Cancer stage } \\
\hline I & $202(21.7)$ & $160(26.9)$ & 0.02 \\
\hline II & 207 (22.3) & $133(22.4)$ & 0.95 \\
\hline III & 176 (18.9) & $109(18.4)$ & 0.8 \\
\hline IV & 216 (23.2) & $126(21.2)$ & 0.4 \\
\hline Unknown & 129 (13.9) & $66(11.1)$ & 0.1 \\
\hline \multicolumn{4}{|l|}{ Cancer site } \\
\hline Bladder & $\leq 5$ & $8(1.3)$ & 0.09 \\
\hline Breast & 99 (10.6) & $111(18.7)$ & $<0.001$ \\
\hline Cervix & $19(2.0)$ & $26(4.4)$ & 0.009 \\
\hline $\begin{array}{l}\text { Chronic lymphocytic } \\
\text { leukemia }\end{array}$ & $\leq 5$ & $\leq 5$ & 0.08 \\
\hline Colorectal & $153(16.4)$ & $87(14.6)$ & 0.3 \\
\hline Kidney & $96(10.3)$ & $40(6.7)$ & 0.02 \\
\hline Lung and bronchus & $131(14.1)$ & $74(12.5)$ & 0.4 \\
\hline $\begin{array}{l}\text { Melanoma of the } \\
\text { skin }\end{array}$ & $\leq 5$ & $\leq 5$ & $\leq 5$ \\
\hline $\begin{array}{l}\text { Non-Hodgkin } \\
\text { lymphoma }\end{array}$ & $33(3.5)$ & $32(5.4)$ & 0.08 \\
\hline Ovary & $25(2.7)$ & $7(1.2)$ & 0.04 \\
\hline Pancreas & $19(2.0)$ & $13(2.2)$ & 0.8 \\
\hline Prostate & $100(10.8)$ & $34(5.7)$ & $<0.001$ \\
\hline Stomach & $18(1.9)$ & $11(1.8)$ & 0.9 \\
\hline Thyroid & $10(1.1)$ & $10(1.7)$ & 0.3 \\
\hline Uterus & $19(2.0)$ & $19(3.2)$ & 0.2 \\
\hline Other & $197(21.2)$ & $113(19.0)$ & 0.3 \\
\hline
\end{tabular}

patients with kidney, ovarian and prostate cancers in the onreserve group than in the off-reserve group.

\section{Cancer incidence and trends}

There were no significant differences in yearly crude or adjusted incidence rates except for 2008/09, in which the offreserve group had a higher adjusted annual incidence of cancer than the on-reserve group (291 v. 380 per $100000, p=$ 0.04 ) (Table 3). The overall adjusted incidence of cancer over the study years was higher in the off-reserve group than in the on-reserve group (287.9 v. 247.9 per $100000, p=0.02)$. The adjusted models controlled for age, sex, income quintile and Regional Health Authority area of residence. There were no significant trends in cancer incidence over time in either group (Table 4).

\section{Cancer mortality}

The on-reserve group had a significantly higher risk of allcause mortality than the off-reserve group (HR 1.28, 95\% CI 1.11 to 1.26); however, there was no significant difference after adjustment for covariates (Table 5). We found no significant difference in the risk of cancer-specific mortality before or after adjustment.

\section{Interpretation}

Among Status First Nations people in Manitoba diagnosed with cancer between 2004/05 and 2010/11, we found that the on-reserve group was on average older and had higher Charlson Comorbidity Index scores than the off-reserve group. A lower proportion of on-reserve patients than offreserve patients were diagnosed at stage $\mathrm{I}$. With the exception of 2008/09, in which cancer incidence was higher in the offreserve group, there were no significant differences in yearly cancer incidence between the 2 groups. However, the adjusted incidence of cancer over all 7 years was higher in the off-reserve group than in the on-reserve group. No differences in mortality were observed.

Table 3: Annual crude and adjusted cancer incidence by location

\begin{tabular}{|c|c|c|c|c|c|c|c|c|}
\hline \multirow[b]{2}{*}{ Year } & \multicolumn{2}{|c|}{ Count } & \multicolumn{2}{|c|}{ Crude IR per 100000} & \multirow[b]{2}{*}{$p$ value } & \multicolumn{2}{|c|}{ Adjusted IR per $100000^{*}$} & \multirow[b]{2}{*}{$p$ value } \\
\hline & On reserve & Off reserve & On reserve & Off reserve & & On reserve & Off reserve & \\
\hline $2004 / 05$ & 116 & 75 & 308.9 & 301.8 & 0.9 & 245.1 & 280.1 & 0.4 \\
\hline $2005 / 06$ & 123 & 71 & 318.6 & 279.7 & 0.4 & 256.3 & 255.4 & 0.98 \\
\hline $2006 / 07$ & 131 & 71 & 330.7 & 273.1 & 0.2 & 260.8 & 247.3 & 0.7 \\
\hline $2007 / 08$ & 121 & 88 & 297.4 & 331.6 & 0.4 & 233.6 & 292.4 & 0.1 \\
\hline $2008 / 09$ & 154 & 119 & 367.2 & 440.0 & 0.1 & 291.0 & 380.3 & 0.04 \\
\hline $2009 / 10$ & 164 & 92 & 378.4 & 329.9 & 0.3 & 307.2 & 280.3 & 0.5 \\
\hline $2010 / 11$ & 159 & 100 & 355.0 & 347.9 & 0.9 & 283.3 & 294.8 & 0.8 \\
\hline Overall & 968 & 616 & 337.8 & 330.4 & 0.7 & 247.9 & 287.9 & 0.02 \\
\hline
\end{tabular}


Table 4: Trend analysis of annual crude and adjusted cancer incidence rates by location

\begin{tabular}{|c|c|c|c|c|}
\hline \multirow[b]{2}{*}{ Measure } & \multicolumn{2}{|c|}{ Crude cancer incidence } & \multicolumn{2}{|c|}{ Adjusted cancer incidence* } \\
\hline & On reserve & Off reserve & On reserve & Off reserve \\
\hline$R^{2}$ & 0.54 & 0.31 & 0.51 & 0.16 \\
\hline $\begin{array}{l}\beta \text { coefficient } \\
(95 \% \mathrm{Cl})\end{array}$ & $10.51(-0.54$ to 21.57$)$ & $\begin{array}{c}14.49(-10.39 \text { to } \\
39.63)\end{array}$ & $8.81(-0.97$ to 18.85$)$ & $8.1(-13.13$ to 29.34$)$ \\
\hline
\end{tabular}

\begin{tabular}{|lc|}
\hline \multicolumn{2}{|l|}{ Table 5: Mortality hazard ratios } \\
\hline Outcome & $\mathrm{HR}(95 \% \mathrm{Cl})^{\star}$ \\
\hline All-cause mortality — crude & $1.28(1.11$ to 1.26$)$ \\
\hline All-cause mortality 5 yr after diagnosis — adjusted & $1.18(0.98$ to 1.41$)$ \\
\hline Cancer-specific mortality — crude & $1.09(0.98$ to 1.22$)$ \\
\hline Cancer-specific mortality 5 yr after diagnosis — adjusted & $1.03(0.90$ to 1.19$)$ \\
\hline $\begin{array}{l}\text { Note: Cl = confidence interval, HR = hazard ratio. } \\
\text { *Adjusted for age, sex, Charlson Comorbidity Index score, cancer stage at diagnosis, income quintile } \\
\text { and Regional Health Authority area of residence. }\end{array}$ \\
\hline
\end{tabular}

We found lower proportions of breast and cervical cancers, both screen-detectable cancers, in the on-reserve group than in the off-reserve group. In Manitoba, there are wellestablished breast and cervical cancer screening programs (www.cancercare.mb.ca/screening/cancer-screening). Breast cancer screening via mammography is recommended every 2 years for women aged $50-74$ years; however, it is available only in larger urban centres in the province; mobile breast cancer screening vans provide services to rural and remote areas on a rotating basis. The on-reserve population is disproportionately rural and remote (Table 2 ), which may contribute to poorer access to mammography screening and fewer diagnoses of breast cancer. However, compared to all other Manitobans, First Nations women are significantly less likely to have had mammography, regardless of urban or rural residency. ${ }^{32}$

Cervical cancer screening via Papanicolaou testing is recommended every 3 years for women aged 21-69 years in Manitoba and is typically done by family physicians in primary care settings. There are notable difficulties in accessing Papanicolaou screening services among Status First Nations women living on reserve, including poor access to family physicians, delivery of health care services on reserve by registered nurses who are not trained to provide Papanicolaou screening, and lack of culturally safe, trauma-informed cervical cancer screening services. ${ }^{33-35}$ These challenges may contribute to lower rates of diagnosis of cervical cancer among Status First Nations women living on reserve.

The lower proportion of on-reserve than off-reserve First Nations people diagnosed with stage I cancers observed in the current study may be related to differential access to health care services. ${ }^{18}$ First Nations people living on reserve are more likely to live in rural and remote areas and to experience difficulties in accessing cancer-related diagnostic and specialty care. ${ }^{36,37}$ Limited local availability of primary care providers, who are seen as essential to referral of patients into specialty oncology care, means that, for many Status First Nations patients, gaining entry "into the system at the 'front end' or diagnostic stage" is a major problem. ${ }^{38}$ Diagnostic care is not available in or within driving distance of most First Nations communities in Manitoba, requiring patients to travel long distances, with considerable disruption to their day-to-day lives. Status First Nations patients living on reserve encounter additional bureaucratic "red tape" and challenges with securing transportation required to access diagnostic and specialty care, ${ }^{37-39}$ which may result in cancer diagnosis at a later stage.

In addition, for many First Nations people (regardless of status), access to health care and cancer services is determined not only by where those services are delivered but also how they are delivered at the point of care. ${ }^{40,41}$ In particular, lack of culturally safe services and frequent experiences of racism substantially affect how and when First Nations people access cancer services. ${ }^{40}$ In contrast, culturally safe approaches to health care recognize the power imbalances within health care that impede access to care ${ }^{41}$ and are grounded in a relational approach to care, in which health care providers and patients work in a partnership and care is provided within environments that are physically and socially safe. ${ }^{42}$

Notably, we found no differences in mortality between Status First Nations peoples living on reserve and those living off reserve. These findings were counterintuitive for our team, as we expected that Status First Nations patients living on reserve would have worse outcomes owing to distance from and accessibility of health care services. We assumed 
that those living off reserve resided in more urban areas and in closer proximity to health care services, and therefore would have better access to health care services and other support services and programs. Our findings seem to suggest that proximity to health care services does not necessarily decrease mortality.

An alternative consideration, raised by our community partners, was that First Nations people tend to be transient, moving back and forth between reserve communities, or between First Nations communities and other communities. Although no definitive conclusions can be drawn based on this consideration, it is important to remember that, despite the listed place of residence (i.e., on v. off reserve), many Status First Nations people have similar experiences in accessing health care services, and our measure for on versus off reserve may not translate well into lived realities.

\section{Limitations}

Study findings are strengthened through our use of multiple population-based and well-validated administrative data sets, which minimized bias related to recall or small samples. We also benefitted from strong relationships with First Nations partners, which enriched our interpretation of findings.

Our findings should be considered in relation to several study limitations. First, we included only Status First Nations people registered under the Indian Act. At present, there is no mechanism to identify non-Status First Nations people in these data sets. Although Status First Nations people represent about $97 \%$ of all First Nations people in Manitoba, ${ }^{43}$ the inclusion of non-Status First Nations people may have resulted in additional differences between groups. We were not able to analyze differences in mortality between First Nations people living on and off reserve by cancer site because of small samples, and there may be substantial differences in mortality depending on cancer site.

We measured income at the area level only, which does not account for individual and family differences. There are always potential inaccuracies involved when aggregate data are used when individual-level data are not available. However, studies in Canada have directly compared individual versus area-based measures and showed that area-level data revealed correlations with health outcomes that were similar to those found with individual-level data, although not as strong. ${ }^{44-46}$ We calculated location of residence at the Regional Health Authority level, which may have obscured important differences between those living in urban versus rural or remote areas within a Regional Health Authority. Categorization into on- or off-reserve residence was based on postal code of residence on a fixed date, and the potential for misclassification of residency exists. As our community partners suggested, First Nations people tend to be highly mobile, moving between reserve and nonreserve communities, which could result in accessing health care services in multiple locations.

Given the data available to us and the retrospective nature of the study, we were not able to adjust for all potentially confounding variables, which may have affected our results.
Ideally, we would have included measures of smoking, alcohol use, physical activity and nutrition, as these are cancer risk factors and proximal measures of more distal determinants of health. Including measures of access to health care, wait times and the cultural safety of care as confounding variables may have also been helpful, as these factors are known to affect First Nations peoples' cancer experiences. ${ }^{38,40}$

Finally, this study included only Status First Nations people living in Manitoba, and the results may not be generalizable to First Nations people living in other Canadian provinces. Although Status First Nations people across Canada experience similar health status, socioeconomic status and health care services, there may be differences in the location of reserve communities or other important differences that hinder the generalizability of our results.

\section{Conclusion}

A lower proportion of Status First Nations patients living on reserve than those living off reserve were diagnosed with cancers at stage I; however, overall cancer incidence over the study years was higher in the off-reserve group. Poor access to primary and diagnostic care among Status First Nations people living on reserve may contribute to fewer early-stage diagnoses and may also result in underreporting of incidence rates. We found no significant differences in 5-year mortality between groups.

Further research is needed to better understand the reasons for differences in stage at diagnosis and overall cancer incidence, particularly in relation to access to health care. Inequities in access to primary and diagnostic care for Status First Nations people living on reserve need attention at the systems and policy levels. In addition, ensuring equitable access to oncology care and developing and implementing culturally safe models of health care for First Nations patients regardless of status and location of residence must be a priority.

\section{References}

1. Tjepkema M, Wilkins R, Senécal S, et al. Mortality of Métis and registered Indian adults in Canada: an 11 year follow-up study. Health Rep 2009;20:31-51.

2. Mazereeuw MV, Withrow DR, Nishri ED, et al. Cancer incidence among First Nations adults in Canada: follow-up of the 1991 census mortality cohort (1992-2009). Can 7 Public Health 2018;109:700-9.

3. Waldram JB, Herring DA, Young TK. Aboriginal health in Canada: historical, cultural, and epidemiological perspectives. 2nd ed. Toronto: University of Toronto Press; 2006.

4. Kelm M. Colonizing bodies: Aboriginal health and bealing in British Columbia 1900-50. Vancouver: UBC Press; 1998.

5. Young TK, Choi NW. Cancer risks among residents of Manitoba. CMAJ $1985 ; 132: 1269-72$.

6. Marrett LD, Chaudhry M. Cancer incidence and mortality in Ontario First Nations, 1968-1991 (Canada). Cancer Causes Control 2003;14:259-68.

7. Louchini R, Beaupre M. Cancer incidence and mortality among Aboriginal people living on reserves and northern villages in Quebec. Int $\mathcal{f}$ Circumpolar Health 2008;67:445-51.

8. McGahan CE, Linn K, Guno P, et al. Cancer in First Nations people living in British Columbia, Canada: an analysis of incidence and survival from 1993 to 2010. Cancer Causes Control 2017;28:1105-16.

9. Rosenberg T, Martel S. Cancer trends from 1972-1991 for Registered Indians living on Manitoba reserves. Int 7 Circumpolar Health 1998;57(Suppl 1):391-8.

10. Chiefs of Ontario, Cancer Care Ontario and Institute for Clinical Evaluative Sciences. Cancer in First Nations people in Ontario: incidence, mortality, survival and prevalence. Toronto: Cancer Care Ontario; 2017. Available: https://www. cancercareontario.ca/sites/ccocancercare/files/assets/CancerFirstNationsReport. pdf (accessed 2018 Apr. 30). 
11. Decker KM, Demers AA, Kliewer EV, et al. Pap test use and cervical cancer incidence in First Nations women living in Manitoba. Cancer Prev Res (Phila) 2015;8:49-55.

12. Young TK, Kliewer E, Blanchard J, et al. Monitoring disease burden and preventive behavior with data linkage: cervical cancer among Aboriginal people in Manitoba, Canada. Am 7 Public Health 2000;90:1466-8.

13. Decker KM, Kliewer EV, Demers AA, et al. Cancer incidence, mortality, and stage at diagnosis in First Nations living in Manitoba. Curr Oncol 2016;23: 225-32.

14. Alvi RA. Breast, cervical and colorectal cancer survival rates for northern Saskatchewan residents and First Nations [thesis]. Saskatoon: University of Saskatchewan; 1999.

15. Sheppard AJ, Chiarelli AM, Marrett LD, et al. Detection of later stage breast cancer in First Nations women in Ontario, Canada. Can 7 Public Health 2010; 101:101-5.

16. Horrill TC, Dahl L, Sanderson E, et al. Comparing cancer incidence, stage at diagnosis and outcomes of First Nations and all other Manitobans: a retrospective analysis. BMC Cancer 2019;19:1055.

17. Erickson B, Biron VL, Zhang H, et al. Survival outcomes of First Nations patients with oral cavity squamous cell carcinoma (Poliquin 2014). 7 Otolaryngol Head Neck Surg 2015;44:4.

18. Withrow DR, Pole JD, Nishri ED, et al. Cancer survival disparities between First Nation and non-Aboriginal adults in Canada: follow-up of the 1991 census mortality cohort. Cancer Epidemiol Biomarkers Prev 2017;26:145-51.

19. Nishri ED, Sheppard AJ, Withrow DR, et al. Cancer survival among First Nations people of Ontario, Canada (1968-2007). Int 7 Cancer 2015;136: 639-45.

20. Elias B, Kliewer EV, Hall M, et al. The burden of cancer risk in Canada's indigenous population: a comparative study of known risks in a Canadian region. Int 7 Gen Med 2011;4:699-709.

21. Decker KM, Demers AA, Kliewer EV, et al. Colorectal cancer screening in First Nations people living in Manitoba. Cancer Epidemiol Biomarkers Prev 2015;24:241-8.

22. Aboriginal Peoples: fact sheet for Canada. Ottawa: Statistics Canada; 2015. Available: http://www.statcan.gc.ca/pub/89-656-x/89-656-x2015001-eng.htm (accessed 2018 July 27).

23. Total population by Aboriginal identity and Registered or Treaty Indian status, Manitoba, 2016 census. Ottawa: Statistics Canada; 2019. Available: https://www12.statcan.gc.ca/ census-recensement/2016/as-sa/fogs-spg/Facts-PR-Eng.cfm?TOPIC=9\&LANG= Eng\&GK=PR\&GC=46\& (accessed 2019 May 24).

24. Lix LM, Smith M, Pitz M, et al. Cancer data linkage in Manitoba: expanding the infrastructure for research. Winnipeg: Manitoba Centre for Health Policy; 2016.

25. Deyo RA, Cherkin DC, Ciol MA. Adapting a clinical comorbidity index for use with ICD-9-CM administrative databases. 7 Clin Epidemiol 1992;45:613-9.

26. Charlson ME, Pompei P, Ales KL, et al. A new method of classifying prognostic comorbidity in longitudinal studies: development and validation. $\mathcal{F}$ Chronic Dis 1987;40:373-83.

27. Frenkel WJ, Jongerius EJ, Mandjes-Van Uitert MJ, et al. Validation of the Charlson Comorbidity Index in acutely hospitalized elderly adults: a prospective cohort study. 7 Am Geriatr Soc 2014;62:342-6.

28. Birim O, Maat APWM, Kappetein AP, et al. Validation of the Charlson Comorbidity Index in patients with operated primary non-small cell lung cancer. Eur 7 Cardiothorac Surg 2003;23:30-4.

29. Singh B, Bhaya M, Stern J, et al. Validation of the Charlson Comorbidity Index in patients with head and neck cancer: a multi-institutional study. Laryngoscope 1997;107:1469-75.

30. Quan H, Sundararajan V, Halfon P, et al. Coding algorithms for defining comorbidities in ICD-9-CM and ICD-10 administrative data. Med Care 2005;43: 1130-9.

31. Edge SB; American Joint Committee on Cancer. A7CC cancer staging manual. 7th ed. New York: Springer; 2010.

32. Demers AA, Decker KM, Kliewer EV, et al. Mammography rates for breast cancer screening: a comparison of First Nations women and all other women living in Manitoba, Canada, 1999-2008. Prev Chronic Dis 2015;12:E82.

33. Black AT. Cervical cancer screening strategies for Aboriginal women. Pimatisiwin 2009;7:157-79. Available: https://journalindigenouswellbeing.com/ media/2018/12/1_Black.pdf (accessed 2018 Sept. 17).

34. Maar M, Burchell A, Little J, et al. A qualitative study of provider perspectives of structural barriers to cervical cancer screening among first nations women. Womens Health Issues 2013;23:e319-25.

35. Wakewich P, Wood B, Davey C, et al. Colonial legacy and the experience of First Nations women in cervical cancer screening: a Canadian multi-community study. Crit Public Health 2016;26:368-80.

36. Minore B, Boone M, Katt M, et al. How clients' choices influence cancer care in northern Aboriginal communities. Int 7 Circumpolar Health 2004;63(Suppl 2):129-32.
37. Saint Elizabeth First Nations, Inuit and Métis Program. "Walk a mile in my moccasins": foundations for action in First Nations cancer control. Toronto: Canadian Partnership Against Cancer; 2012. Available: http://www.cancerview.ca/idc/ groups/public/documents/webcontent/fnim_cancer_ctrl_on_res.pdf (accessed 2018 Jan. 17).

38. The cancer story: Canadian Cancer Control in First Nations populations living off-reserve in rural, remote and isolated areas. Winnipeg: CancerCare Manitoba; 2013. Available: https://dev.partnershipagainstcancer.ca/wp-content/ uploads/2018/12/cancer_story_first_nations_off_reserve_EN.pdf (accessed 2017 Nov. 14).

39. Lavoie JG, Kaufert J, Browne AJ, et al. Managing Matajoosh: determinants of First Nations' cancer care decisions. BMC Health Serv Res 2016;16:402.

40. Horrill TC, Linton J, Lavoie JG, et al. Access to cancer care among Indigenous Peoples in Canada: a scoping review. Soc Sci Med 2019;238:112495.

41. Horrill T, Mcmillan DE, Schultz ASH, et al. Understanding access to healthcare among Indigenous peoples: a comparative analysis of biomedical and postcolonial perspectives. Nurs Inq 2018;25:e12237.

42. Brooks-Cleator L, Phillipps B, Giles A. Culturally safe health initiatives for Indigenous Peoples in Canada: a scoping review. Can 7 Nurs Res 2018;50: 202-13.

43. Manitoba [province] and Canada [country] (table). Census profile. 2016 census. Ottawa: Statistics Canada; 2017. Cat no 98-316-X2016001.

44. Mustard CA, Derksen S, Berthelot JM, et al. Assessing ecologic proxies for household income: a comparison of household and neighbourhood level income measures in the study of population health status. Health Place 1999;5:157-71.

45. Pampalon R, Hamel D, Gamache P. A comparison of individual and areabased socio-economic data for monitoring social inequalities in health. Health Rep 2009;20:85-94.

46. Pampalon R, Hamel D, Gamache P. Health inequalities in urban and rural Canada: comparing inequalities in survival according to an individual and areabased deprivation index. Health Place 2010;16:416-20.

Affiliations: College of Nursing (Horrill, Thompson, Schultz), Rady Faculty of Health Sciences, University of Manitoba; Rady Faculty of Health Sciences (Dhal, Cook), University of Manitoba, Winnipeg, Man.; University College of the North (Sanderson); Cree Nation Tribal Health Centre (Munro), The Pas, Man.; Interlake Reserves Tribal Council (Garson); Manitoba Centre for Health Policy (Fransoo), University of Manitoba; Indigenous Health Library (Linton), University of Manitoba, Winnipeg, Man.

Contributors: Tara Horrill and Annette Schultz conceived the study. Tara Horrill, Randy Fransoo and Annette Schultz designed the study. Tara Horrill, Lindsey Dahl, Randy Fransoo and Annette Schultz drafted the manuscript. Esther Sanderson, Garry Munro, Cindy Garson, Genevieve Thompson, Catherine Cook and Janice Linton revised the manuscript critically for important intellectual content. All of the authors analyzed and interpreted the data, approved the final version to be published and agreed to be accountable for all aspects of the work.

Funding: This research was funded by grant UM\#47075 from the University Indigenous Research Program, University of Manitoba. Tara Horrill is supported by a University of Manitoba Graduate Fellowship and a Research Manitoba doctoral fellowship.

Acknowledgement: The authors acknowledge Carole Taylor and the Manitoba Centre for Health Policy for use of data in the Manitoba Population Research Data Repository.

Disclaimer: Data used in this study are from the Manitoba Population Research Data Repository housed at the Manitoba Centre for Health Policy, University of Manitoba, and were derived from data provided by Manitoba Health, Vital Statistics, Statistics Canada and CancerCare Manitoba. The results and conclusions are those of the authors, and no official endorsement by the Manitoba Centre for Health Policy, Manitoba Health or other data providers is intended or should be inferred. The funders had no role in the study design, collection, analysis and interpretation of data, or in the writing of the manuscript.

Supplemental information: For reviewer comments and the original submission of this manuscript, please see www.cmajopen.ca/content/7/4/ E754/suppl/DC1. 